\title{
Behavior of Three-Phase Inverters under Grid Faults Explained from a Geometric Perspective
}

\author{
Alejandro Rolán \\ Serra Húnter Fellow \\ Department of Automatic Control \\ Technical University of Catalonia \\ Barcelona, Spain \\ alejandro.rolan@upc.edu
}

\begin{abstract}
The aim of this work is to analyze the dynamic behavior of inverters powered by renewable energy sources (RES) operating under grid faults by means of a geometric point of view. To this purpose, a three-phase grid-connected inverter subject to voltage sags is analyzed. First, the mathematical equations that describe its electrical model under voltage sags are given in the complex form of the transformed Park components. Second, simulations results show the resemblance between the curve depicted by the transformed Park components of the injected currents in the complex plane and well-known geometric curves. Finally, the geometric-based approach is used to describe easily the dynamic behavior of grid-connected inverters under voltage sags. This new approach could be used to propose new control techniques to achieve fault ride-through (FRT) capability of three-phase inverters.
\end{abstract}

Keywords-Distributed energy resource (DER), geometry, inverter, limaçon, renewable energy source (RES), voltage sag.

\section{INTRODUCTION}

In the current path towards a decarbonized society, the use of renewable energies (e.g. wind or photovoltaic (PV) energy) has emerged as the eco-friendly alternative to power the world. Studies reveal that about $60 \%$ of total generation in 2050 might be produced by renewable energy sources (RES) [1]. As a result, numerous publications have arisen from the last two decades in order to deal with the integration of RES into the main grid, specially concerning the topics of grid synchronization [2], [3], operation within microgrids [4], [5] and, with growing attention, their control under grid faults, which is comprehensively explained in [6].

Voltage sags (or dips) are mainly caused by grid faults and they are defined as a decrease in the rms value of voltage between $10 \%$ and $90 \%$ of the pre-fault steady state value for durations from a half cycle to one minute [7]. If this voltage decrease is the same in the three phases, the voltage sag is symmetrical. Otherwise, it is unsymmetrical. Table I (adapted from [8]) shows the voltage sag classification according to the grid faults that cause them. The effects of voltage sags on gridconnected equipment are well known in the literature: torque peaks in rotating machines [9], saturation in transformers [10], and DC-link fluctuations in voltage-source inverter (VSI) adjustable-speed drives [11], among others.

The voltage sag effects on grid-connected inverters powered by RES have been studied over the last years and different solutions have been proposed to limit the high current peaks, which can damage the system. Take the examples, among others, of using a decoupled current control technique to govern, separately, the positive- and negativesequence components of the injected current [12], [13] or considering the grid code requirements to control both active

This work was supported in part by the Spanish Ministry of Science, Innovation and Universities under grant RTI2018-095720-B-C33 and in part by the Spanish Ministry of Economy and EU FEDER Funds under grant DPI2017-84503-R.

978-1-7281-9023-5/21/\$31.00 (C2021 IEEE and reactive currents [14], [15]. Other studies have focused their attention on providing an analytical study to describe the dynamic behavior of the system under voltage sags, such as doubly-fed induction generation (DFIG)-based wind turbines (WTs) under symmetrical and unsymmetrical voltage sags, respectively [16], [17].

It should be noted that recent analytical approaches in the technical literature regarding three-phase inverters under grid faults have paid special attention to justify a proper control for both positive- and negative-sequence components with current limitation to achieve fault ride-through (FRT) [18], [19]. However, there are no analytical studies in the technical literature that analyze the behavior of grid-connected inverters under voltage sags from a geometric perspective. This study uses the author's previous works [20], [21] in order to develop a novel analytical approach, by means of which it is proved the correspondence between the limaçon of Pascal curve and the geometric figure drawn by the injected current in the complex plane during voltage sags. Then, this powerful tool can be used to propose new control techniques (or to improve the existing ones) to make three-phase grid-connected inverters achieve FRT in an understandable way.

\section{MOdEL OF THE STUdied GRID-CONNECTED INVERTER}

The studied three-phase grid-connected inverter is depicted in Fig. 1. It consists of: a constant current source, which emulates the RES (wind or PV), a DC link, a power converter (DC-to-AC, i.e., inverter), a resistive-inductive (RL) filter and the grid (which is modelled as an AC voltage source). The electrical equations that describe the behavior of the inverter in abc components can be written by the following matrix equation (assuming the generator-sign convention):

$$
\left[v_{\mathrm{i} \mathrm{abc}}\right]=[R]\left[i_{\mathrm{abc}}\right]+\mathrm{s}[L]+\left[v_{\mathrm{g} a b c}\right]
$$

where $v_{\mathrm{i} \text { abc }}$ is the inverter output voltage, $v_{\mathrm{g} \text { abc }}$ is the grid voltage, $R$ and $L$ are the filter resistance and reactance, respectively, $i_{\mathrm{abc}}$ is the injected current and $\mathrm{s}=\mathrm{d} / \mathrm{d} t$ is the derivative operator. According to the author's previous work [20], [21], if (1) is written in the complex form of the transformed Park variables, the following expression is obtained:

$$
v_{\text {if }}=[R+L(\mathrm{~s}+\mathrm{j} \omega)] i_{\mathrm{f}}+v_{\mathrm{gf}}
$$

where $\omega=2 \pi f$ is the grid voltage pulsation ( $f$ is the grid frequency) and the subscript $\mathrm{f}$ stands for the forward component of the transformed $K u$ variable, which equals the complex form of the transformed Park variable, according to:

$$
x_{\mathrm{f}}=\frac{1}{\sqrt{2}}\left(x_{\mathrm{d}}+\mathrm{j} x_{\mathrm{q}}\right)
$$




\begin{tabular}{|c|c|c|c|}
\hline Sag type & Fault type & Phasor & Seq. components \\
\hline A & $\begin{array}{c}\text { 3-phase fault } \\
\text { 3-phase-to-ground fault }\end{array}$ & & $\begin{array}{l}\underline{V}_{\mathrm{A}}^{0}=0 \\
\underline{V}_{\mathrm{A}}^{+}=h \underline{V} \\
\underline{V}_{\mathrm{A}}^{-}=0\end{array}$ \\
\hline B & 1-phase-to-ground fault & & $\begin{array}{l}\underline{V}_{\mathrm{B}}^{0}=-\frac{1-h}{3} \underline{V} \\
\underline{V}_{\mathrm{B}}^{+}=\frac{2+h}{3} \underline{V} \\
\underline{V}_{\mathrm{B}}^{-}=-\frac{1-h}{3} \underline{V}\end{array}$ \\
\hline $\mathrm{C}$ & $\begin{array}{l}\text { 2-phase fault } \\
\text { 1-phase-to-ground fault } \\
\text { after a Dy transformer }\end{array}$ & & $\begin{array}{l}\underline{V}_{\mathrm{C}}^{0}=0 \\
\underline{V}_{\mathrm{C}}^{+}=\frac{1+h}{2} \underline{V} \\
\underline{V}_{\mathrm{C}}^{-}=\frac{1-h}{2} \underline{V}\end{array}$ \\
\hline $\mathrm{D}$ & $\begin{array}{c}\text { 2-phase fault after a Dy } \\
\text { transformer } \\
\text { 1-phase-to-ground fault } \\
\text { after two Dy transformers }\end{array}$ & b & $\begin{array}{l}\underline{V}_{\mathrm{D}}^{0}=0 \\
\underline{V}_{\mathrm{D}}^{+}=\frac{1+h}{2} \underline{V} \\
\underline{V}_{\mathrm{D}}^{-}=-\frac{1-h}{2} \underline{V}\end{array}$ \\
\hline $\mathrm{E}$ & 2-phase-to-ground fault & & $\begin{array}{l}\underline{V}_{\mathrm{E}}^{0}=\frac{1-h}{3} \underline{V} \\
\underline{V}_{\mathrm{E}}^{+}=\frac{1+2 h}{3} \underline{V} \\
\underline{V}_{\mathrm{E}}^{-}=\frac{1-h}{3} \underline{V}\end{array}$ \\
\hline $\mathrm{F}$ & $\begin{array}{l}\text { 2-phase-to-ground fault } \\
\text { after a Dy transformer }\end{array}$ & b & $\begin{array}{l}\underline{V}_{\mathrm{F}}^{0}=0 \\
\underline{V}_{\mathrm{F}}^{+}=\frac{1+2 h}{3} \underline{V} \\
\underline{V}_{\mathrm{F}}^{-}=-\frac{1-h}{3} \underline{V}\end{array}$ \\
\hline G & $\begin{array}{l}\text { 2-phase-to-ground fault } \\
\text { after two Dy transformers }\end{array}$ & b & $\begin{array}{l}\underline{V}_{\mathrm{G}}^{0}=0 \\
\underline{V}_{\mathrm{G}}^{+}=\frac{1+2 h}{3} \underline{V} \\
\underline{V}_{\mathrm{G}}^{-}=\frac{1-h}{3} \underline{V}\end{array}$ \\
\hline
\end{tabular}

with $x$ being the variable of interest, and subscripts $\mathrm{d}$ and $\mathrm{q}$ stand for the direct and quadrature components, respectively, of the transformed Park variable.

It should be noted from (2) that the term $v_{\mathrm{gf}}$ corresponds to the forward component of the transformed $K u$ grid voltage, which can be expressed as (see the [20], [21] for more details):

$$
v_{\text {gf }}=v_{\text {gf }}^{+}+v_{\text {gf }}^{-} \mathrm{e}^{-\mathrm{j} 2 \omega t}
$$

where $v_{\mathrm{gf}}{ }^{+}$and $v_{\mathrm{gf}}{ }^{-}$are given by:

$$
v_{\mathrm{gf}}^{+}=\sqrt{3 / 2} \underline{V}^{+} \quad ; \quad v_{\mathrm{gf}}^{-}=\sqrt{3 / 2}\left(\underline{V}^{-}\right)^{*}
$$

with $\underline{V}^{+}$and $\underline{V}^{-}$being the sequence components of voltage sags, which are given in the rightmost column of Table I, and the superscript ${ }^{*}$ stands for the complex conjugate.

Assuming that the transformed inverter voltage $\left(v_{\mathrm{if}}\right)$ equals its pre-fault steady-state value during all the entire transient, then (2) becomes a first-order ordinary differential equation (ODE) with constant coefficients, whose solution is (see the author's previous works [20], [21]):

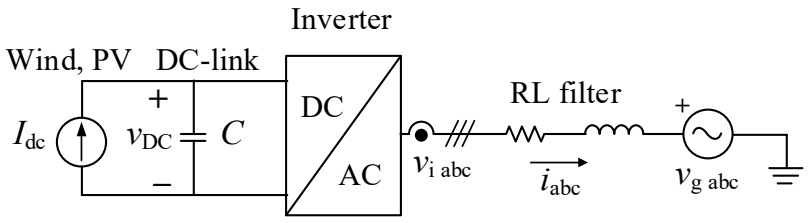

Fig. 1. Electrical scheme of the studied three-phase grid-connected inverter (generator-sign convention).

$$
\begin{array}{ll}
i_{\mathrm{f}}=\frac{v_{\mathrm{if}}-v_{\mathrm{gf} \mathrm{st}}}{R+\mathrm{j} \omega L} & ; \quad\left(t<t_{\mathrm{i}}\right) \\
i_{\mathrm{f}}=\underline{K}_{1} \mathrm{e}^{-(R / L)\left(t-t_{\mathrm{i}}\right)} \mathrm{e}^{-\mathrm{j} \omega\left(t-t_{\mathrm{i}}\right)}-\underline{K}_{2} \mathrm{e}^{-\mathrm{j} 2 \omega t}+\underline{K}_{3} & ; \quad\left(t_{\mathrm{i}} \leq t<t_{\mathrm{f}}\right) \\
i_{\mathrm{f}}=\underline{K}_{4} \mathrm{e}^{-(R / L)\left(t-t_{\mathrm{f}}\right)} \mathrm{e}^{-\mathrm{j} \omega\left(t-t_{\mathrm{f}}\right)}+\underline{K}_{5} & ;\left(t \geq t_{\mathrm{f}}\right)
\end{array}
$$

where the complex constants are given by:

$$
\begin{aligned}
& \underline{K}_{1}=\frac{v_{\mathrm{gf}}^{+}-v_{\mathrm{gf} \mathrm{st}}}{R+\mathrm{j} \omega L}+\underline{K}_{2} \mathrm{e}^{-\mathrm{j} 2 \omega t_{\mathrm{i}}} ; \underline{K}_{2}=\frac{v_{\mathrm{gf}}^{-}}{R-\mathrm{j} \omega L} ; \underline{K}_{3}=\frac{v_{\mathrm{if}}-v_{\mathrm{gf}}^{+}}{R+\mathrm{j} \omega L} \\
& \underline{K}_{4}=\underline{K}_{1} \mathrm{e}^{-(R / L)\left(t_{\mathrm{f}}-t_{\mathrm{i}}\right)} \mathrm{e}^{-\mathrm{j} \omega\left(t_{\mathrm{f}}-t_{\mathrm{i}}\right)}-\underline{K}_{2} \mathrm{e}^{-\mathrm{j} 2 \omega t_{\mathrm{f}}}+\underline{K}_{6} \\
& \underline{K}_{5}=\frac{v_{\mathrm{if}}-v_{\mathrm{gf} \mathrm{st}}}{R+\mathrm{j} \omega L} ; \underline{K}_{6}=\frac{v_{\mathrm{gf} \mathrm{st}}-v_{\mathrm{gf}}^{+}}{R+\mathrm{j} \omega L}
\end{aligned}
$$

where superscripts + and - stand for the positive- and negative-sequence components, respectively, of the transformed variable, $t_{\mathrm{i}}$ (initial time) is the time when the sag starts, $t_{\mathrm{f}}$ (final time) is the time when the sag ends and the subscript st stands for steady-state conditions. It should be noted that for symmetrical sags there is no negative-sequence component. So, the term with $\underline{K}_{2}$ is zero and there is no pulsation that equals twice the fundamental pulsation. It should also be noted that sags with abrupt (or instantaneous) voltage recovery are assumed for this study. The analysis of grid-connected inverters under voltage sags with discrete voltage recovery can be found in [20].

\section{GRID-CONNECTED INVERTER SUBJeCt to SAGS}

A $50-\mathrm{kW}$ three-phase inverter operating with unitary power factor connected to a stiff grid with rated values $400 \mathrm{~V}$ (phase-to-phase) and $50 \mathrm{~Hz}$ is considered. The output filter has a resistance of $1 \mathrm{~m} \Omega$ and an inductance of $5 \mathrm{mH}$. The inverter is simulated operating under steady-state conditions until a voltage sag occurs at $t=2 T$ (where $T=1 / f$ is the grid voltage period). All voltage sag types (Table I) have been simulated with a voltage decrease of $30 \%$ (i.e. with a sag depth $h=0.7$ ) and a duration of 5 cycles (i.e. $\Delta t=5 T$ ).

The analytical model (6)-(8) has been simulated by means of the MATLAB ${ }^{\mathrm{TM}}$ software. The obtained simulation results are depicted in Fig. 2, where it is shown the behavior of the injected current by the inverter before the sag, during the sag, and once it has been cleared: time evolution of the abc components of the injected current (Fig. 2a), time evolution of real and imaginary parts of the transformed forward component (Fig. 2b), and real part vs. imaginary part in the complex plane (Fig. 2c). The results are shown in per unit according to:

$$
i_{\mathrm{f}(\mathrm{pu})}=\frac{i_{\mathrm{f}}}{\sqrt{3 / 2} I_{\mathrm{N}}} \quad ; \quad i_{\mathrm{abc}(\mathrm{pu})}=\frac{i_{\mathrm{abc}}}{\sqrt{2} I_{\mathrm{N}}}
$$

with $I_{\mathrm{N}}$ being the rated current of the inverter. 

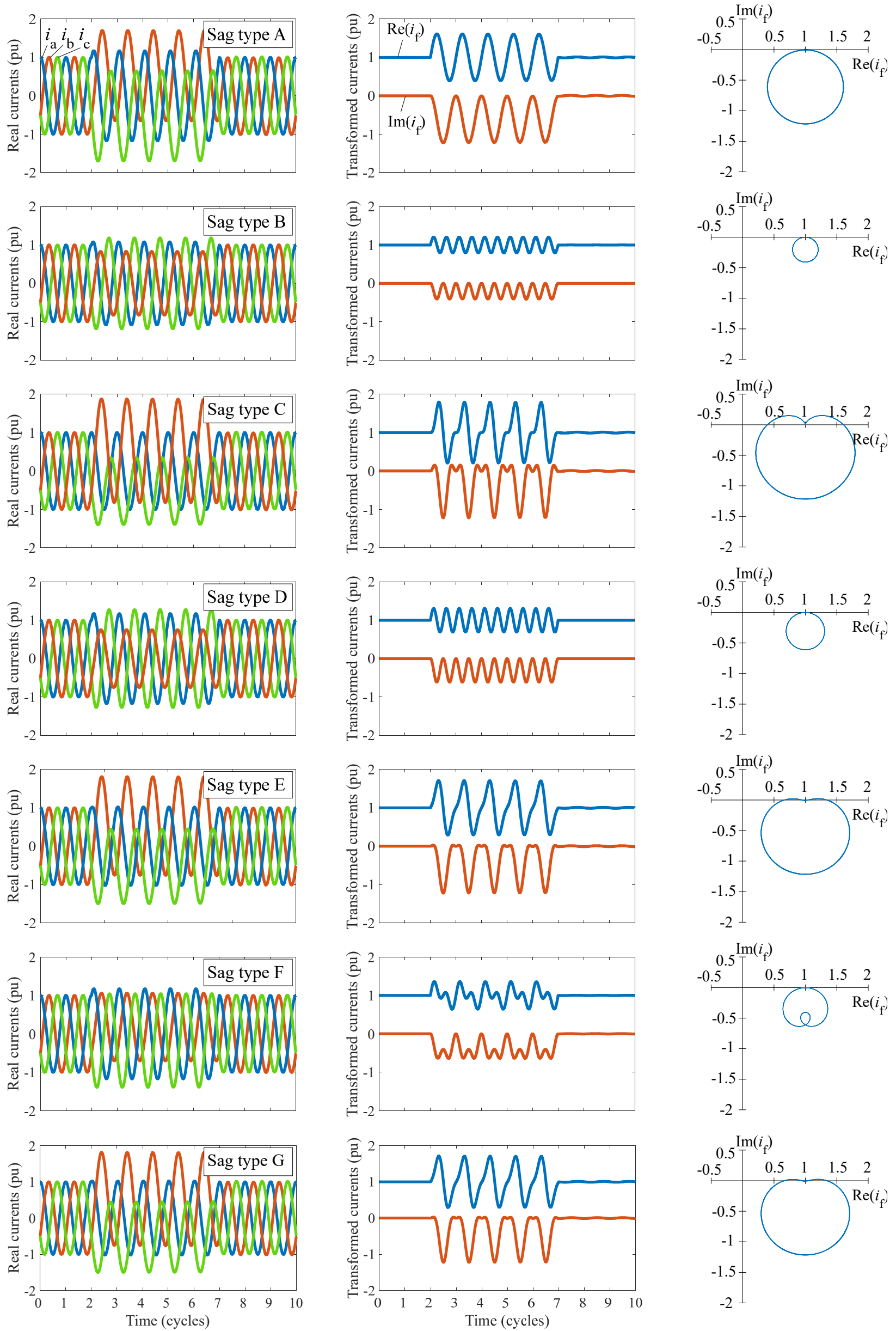

(a)

(b)

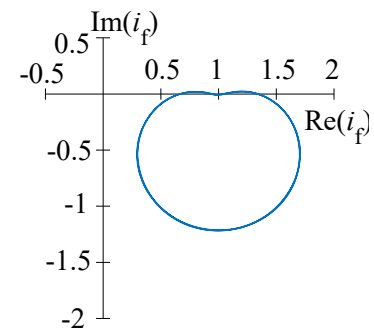

(c)

Fig. 2. Injected currents by the studied three-phase grid-connected inverter subject to voltage sags. All sag types have been simulated with a depth $h=0.7$, with a duration $\Delta t=5$ cycles and with an initial time $t=2$ cycles. (a) Time evolution of the abc components of the injected current, (b) time evolution of the transformed current (real and imaginary part), and (c) real part vs. imaginary part of the transformed current in the complex plane. 


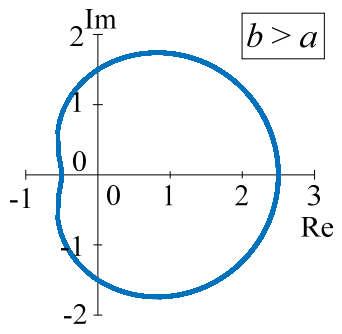

(a)

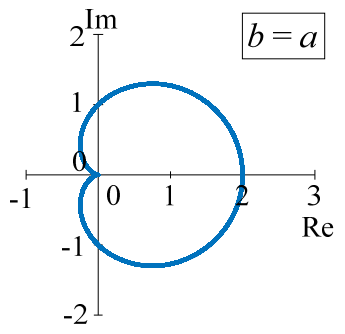

(b)

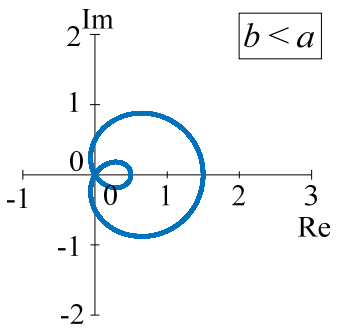

(c)

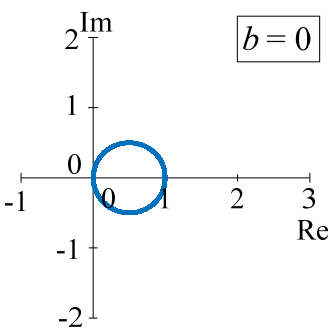

(d)

Fig. 3. Curves obtained by the limaçon of Pascal equation with different values of $a$ and $b$. (a) Closed dimpled curve $(b=3 / 2$ a); (b) cardioid ( $b=a)$; (c) curve with an inner loop $(b=a / 2)$; and (d) circle $(b=0)$.

Judging by the Fig. 2 results, the following comments can be made:

(a) there is a noticeable increase in the current during the sag, which is due to the reduction in the rms value of the grid voltage;

(b) the abc components of the current (Fig. 2a) are balanced before and after the sag (steady-state conditions), but they are unbalanced during the sag;

(c) this imbalance in the abc components of the current causes a pulsation in the transformed current during the fault (Fig. 2b), which equals the fundamental pulsation in the case of symmetrical sags (A type) and twice the fundamental pulsation for unsymmetrical sags (B...G types), which is corroborated by the exponential term with $-\mathrm{j} 2 \omega t$ shown in (7);

(d) the most severe effects on the inverter are given by sag types A, C, E and G, because the current peaks are the highest ones;

(e) sag types E and G cause the same behavior on the current (this is due to the fact that there is no zero-sequence component on the grid-connected inverter, so according to Table I the sequence components of the voltage for these sag types are the same);

(f) sag types B and D cause similar behavior on the current (note from Table I that if there is no zero-sequence component, then sag type $\mathrm{D}$ with depth $h$ from $1 / 3$ to 1 has the same positive- and negative-sequence voltages as sag type B with depth $h$ from 0 to 1 );

(g) although not properly seen in Fig. 2 results, both time evolution of the currents and its behavior in the complex plane present a damping, which is due to the time constant $R / L$ attested in (7);

(h) plotting the transformed currents in the complex plane (Fig. 2c) gives rise to geometric curves, which can be easily identified by their Cartesian and complex equations, as explained in the following section.

\section{GEOMETRIC APPROACH}

\section{A. Limaçon of Pascal}

The limaçon (or limacon) of Pascal is defined geometrically as the conchoid of a circle of radius a with respect to an origin point on the circumference of the circle [22]. The limaçon of Pascal written in polar coordinates is:

$$
r=b+a \cos (\theta)
$$

where a is the radius of the circle, $b$ is the parameter of the conchoid and $\theta$ is the angle of rotation. The Cartesian equations of the limaçon of Pascal can be obtained from the polar equation (13) by using $x=r \cos (\theta)$ and $\mathrm{y}=r \sin (\theta)$, yielding:

$$
\begin{aligned}
& x=r \cos (\theta)=[b+a \cos (\theta)] \cos (\theta) \\
& y=r \sin (\theta)=[b+a \cos (\theta)] \sin (\theta)
\end{aligned}
$$

which can be written according to the trigonometric identities $\cos ^{2}(\theta)=(1+\cos (2 \theta)) / 2$ and $\cos (\theta) \sin (\theta)=\sin (2 \theta) / 2$ as:

$$
\begin{aligned}
& x=\frac{a}{2}+b \cos (\theta)+\frac{a}{2} \cos (2 \theta) \\
& y=b \sin (\theta)+\frac{a}{2} \sin (2 \theta) .
\end{aligned}
$$

Finally, the limaçon of Pascal can be given in the complex plane by setting $z=x+\mathrm{j} y$. So, considering (16) and (17) and the Euler formula $\mathrm{e}^{\mathrm{j} \theta}=\cos (\theta)+\mathrm{j} \sin (\theta)$, we obtain:

$$
z=x+\mathrm{j} y=\frac{a}{2}+b \mathrm{e}^{\mathrm{j} \theta}+\frac{a}{2} \mathrm{e}^{\mathrm{j} 2 \theta} .
$$

Fig. 3 shows the curves that can be obtained by giving different values of $a$ and $b$ to the limaçon of Pascal (18). The following observations can be made from the graphic:

(a) If $b>a$, the limaçon is a closed dimpled curve (Fig. 3a);

(b) if $b=a$, the limaçon is a closed curve with a cusp, i.e., a cardioid (Fig. 3b);

(c) if $b<a$, the cusp of the limaçon becomes an inner loop and the resulting curve crosses itself at one point (Fig. 3c);

(d) if $b=0$, the limaçon becomes a circle (Fig. 3d).

\section{B. Behavior of Grid-Connected Inverters under Voltage Sags Explained from a Geometric Perspective}

As explained in Section III, the studied three-phase inverter injects currents during sags that perform geometric curves in the complex plane (Fig. 2c), although these curves are damped by the time constant $R / L$ of the filter, as observed in (7). However, we could make the assumption that $R<<L$, and given that the sag duration is assumed to be small (some cycles), then the damping can be neglected. By doing so, and considering that the initial time when the sag starts is $t_{\mathrm{i}}=0$, the expression of the transformed current during the voltage sag (7) can be written as:

$$
i_{\mathrm{f}}=\frac{\mathrm{j}}{X}\left[\left(v_{\mathrm{gf}}^{+}-v_{\text {if }}\right)+\left(v_{\mathrm{gf} \mathrm{st}}-v_{\mathrm{gf}}^{+}+v_{\mathrm{gf}}^{-}\right) \mathrm{e}^{-\mathrm{j} \omega t}-v_{\mathrm{gf}}^{-} \mathrm{e}^{-\mathrm{j} 2 \omega t}\right]
$$

where $X=\omega L$ is the filter reactance. 
TABle II. Voltage Sags that Cause Each Limaçon of Pascal

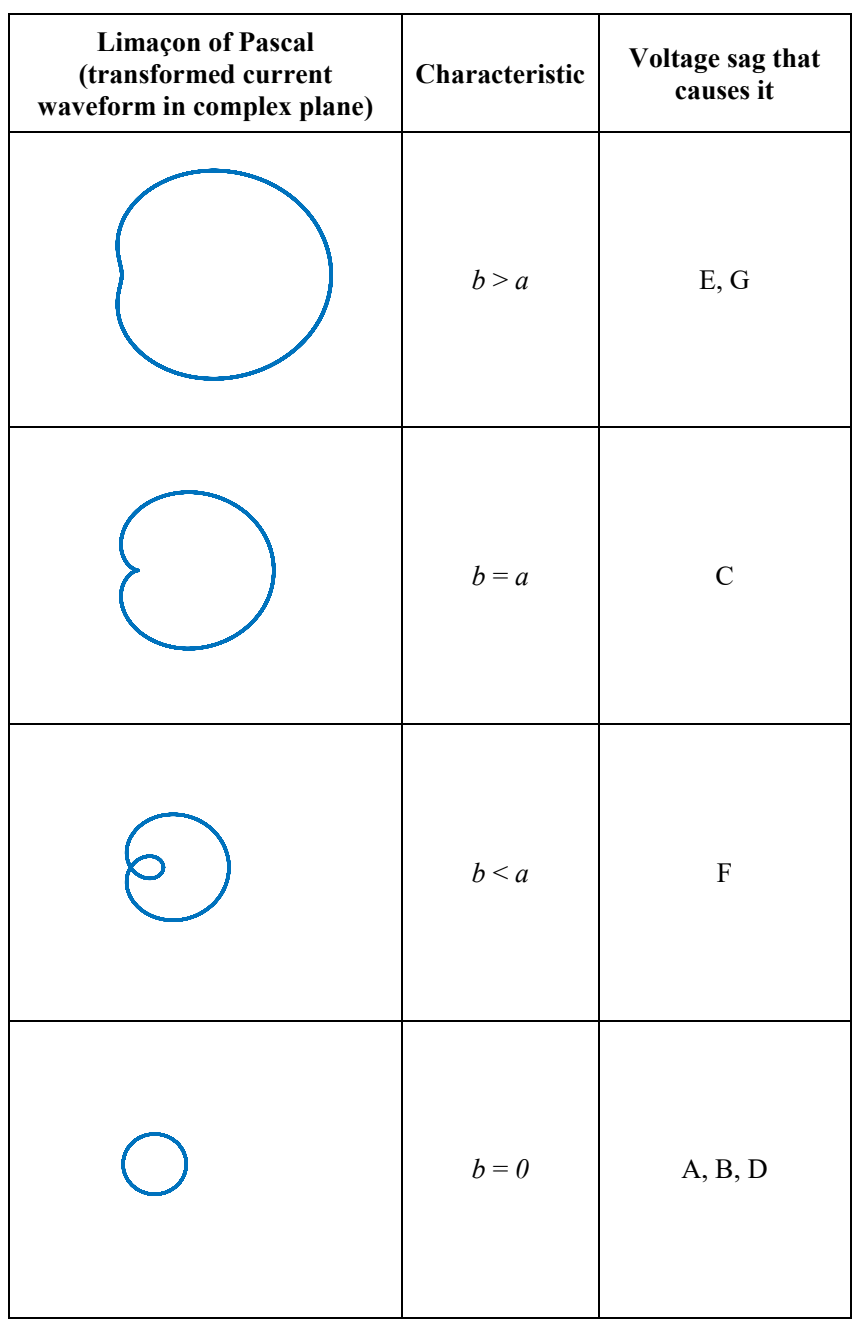

The previous equation shows a resemblance with the complex equation of the limaçon of Pascal (18). There are only two differences. First, in (19) the equation is multiplied by $\mathrm{j} / X$, which causes a rotation of $90 \mathrm{deg}$. in the complex plane (it can be observed if comparing the curves of Fig. 3 with the curves of Fig. 2c). Second, in (19) the exponential terms include $-\mathrm{j}$, while in (18) the exponential term include $\mathrm{j}$ (however, it only indicates that in one case the curve is obtained counter-clockwise and in the other case the curve is obtained clockwise, but it does not change the curve itself). Then, by comparing (18) and (19), the following identities can be written:

$$
\begin{aligned}
& \frac{a}{2}=\frac{\mathrm{j}}{X}\left(v_{\mathrm{gf}}^{+}-v_{\mathrm{if}}\right)=\frac{\mathrm{j}}{X}\left(-v_{\mathrm{gf}}^{-}\right) \rightarrow a=\frac{2 \mathrm{j}}{X}\left(v_{\mathrm{gf}}^{+}-v_{\mathrm{if}}\right)=-\frac{2 \mathrm{j}}{X} v_{\mathrm{gf}}^{-} \\
& b=\frac{\mathrm{j}}{X}\left(v_{\mathrm{gf} \mathrm{st}}-v_{\mathrm{gf}}^{+}+v_{\mathrm{gf}}^{-}\right) .
\end{aligned}
$$

The behavior of three-phase grid-connected inverters under voltage sags could be explained just by equation (13) in polar coordinates or by equation (18) in the complex plane, where $a$ and $b$ are the complex constants given in (20). Moreover, depending on the values of $a$ and $b$, the behavior of the injected current under voltage sags will be different. Then, by comparing the curves of Fig. 3 with the ones shown in Fig. $2 \mathrm{c}$ the conclusions summarized in Table II can be drawn.
Finally, it should be noted that the analysis explained in this work could also be done for modular multilevel converters (MMCs) operating under either balanced or unbalanced grid conditions. In order to do so, it is necessary first to obtain an equivalent MMC circuit that emulates the behavior of all diode-clamp submodules (SMs) plus the protection thyristors. By using this equivalent circuit, the upper arms of the MMC will behave like a three-phase half-wave rectifier when the protection thyristors are fired [23]. Note also that this kind of analysis might be especially important when analyzing the behavior of MMCs with floating capacitors [24] under unbalanced faults [25], because the device might be damaged due to large current peaks and DC voltage ripples (which will appear as a consequence of twice the fundamental frequency) might cause a loss of controllability.

\section{CONCLUSION}

This paper has presented a new approach to predict the behavior of grid-connected three-phase inverters subject to voltage sags by means of using a simple equation that models a geometric curve. Both analytical model and simulation results of a three-phase inverter with an RL filter operating under a faulty grid with both symmetrical and unsymmetrical faults corroborate the resemblance between the behavior of the transformed current in the complex plane and the curve called limaçon of Pascal. This new approach could be used in an easy and understandable way to propose new control techniques (or to improve the existing ones) to achieve fault ride-through capability for three-phase inverters operating under grid faults.

\section{REFERENCES}

[1] International Renewable Energy Agency (IRENA), Global energy transformation. A roadmap to 2050, Tech. Rep., Apr. 2019. [Online]. Available: http://www.irena.org/. Accessed on: Feb. 15, 2021.

[2] F. Blaabjerg, R. Teodorescu, M. Liserre, and A. V. Timbus, "Overview of control and grid synchronization for distributed power generation systems," IEEE Trans. Ind. Electron., vol. 53, no. 5, pp. 1398-1409, Oct. 2006.

[3] P. Rodríguez, A. Luna, R. S. Muñoz-Aguilar, I. Etxeberria-Otadui, R. Teodorescu, and F. Blaabjerg, "A stationary reference frame grid synchronization system for three-phase grid-connected power converters under adverse grid conditions," IEEE Trans. Power Electron., vol. 27, no. 1, pp. 99-112, Jan. 2012.

[4] J. Rocabert, A. Luna, F. Blaabjerg, and P. Rodríguez, "Control of power converters in ac microgrids," IEEE Trans. Power Electron., vol. 27, no. 11, pp. 4734-4749, Nov. 2012.

[5] D. Wu, F. Tang, T. Dragicevic, J. C. Vasquez, and J. M. Guerrero, “A control architecture to coordinate renewable energy sources and energy storage systems in islanded microgrids," IEEE Trans. Smart Grid, vol. 6, no. 3, pp. 1156-1166, May 2015.

[6] R. Teodorescu, M. Liserre, and P. Rodríguez, Grid Converters for Photovoltaic and Wind Power Systems. Chichester, WS, UK: WileyIEEE Press, 2011, pp. 237-287.

[7] IEEE Recommended Practice for Monitoring Electric Power Quality. IEEE Std. 1159-2019, IEEE, 2019.

[8] M. H. J. Bollen, Understanding Power Quality Problems: Voltage Sags and Interrumptions. NY, NY, USA: Wiley-IEEE Press, 2000, pp. 139-251.

[9] L. Guasch, F. Córcoles, and J. Pedra, "Effects of symmetrical and unsymmetrical voltage sags on induction machines," IEEE Trans. Power Deliv., vol. 19, no. 2, pp. 774-782, Apr. 2004

[10] L. Guasch, F. Córcoles, J. Pedra, and L. Sáinz, "Effects of symmetrical voltage sags on three-phase three-legged transformers," IEEE Trans. Power Deliv., vol. 19, no. 2, pp. 875-883, Apr. 2004.

[11] J. Pedra, F. Córcoles, and F. J. Suelves, "Effects of balanced and unbalanced voltage sags on vsi-fed adjustable-speed drives," IEEE Trans. Power Deliv., vol. 20, no. 1, pp. 224-233, Jan. 2005.

[12] H.-S. Song and K. Nam, "Dual current control scheme for pwm converter under unbalanced input voltage conditions," IEEE Trans. Ind. Electron., vol. 46, no. 5, pp. 953-959, Oct. 1999. 
[13] A. Junyent-Ferré, O. Gomis-Bellmunt, T. C. Green, and. D. E. SotoSánchez, "Current control reference calculation issues for the operation of renewable source grid interface vscs under unbalanced voltage sags," IEEE Trans. Power Electron., vol. 26, no. 12, pp. 3744-3753, Dec. 2011.

[14] M. Bakkar, S. Bogarra, A. Rolán, F. Córcoles, and J. Saura, "Voltage sag influence on controlled three-phase grid-connected inverters according to the Spanish grid code," IET Gener. Transm. Distrib., vol. 14, no. 10, pp. 1882-1892, May 2020.

[15] S. I. Nanou and S. A. Papathanassiou, "Grid code compatibility of vsc-hvdc connected offshore wind turbines employing power synchronization control," IEEE Trans. Power Syst., vol. 31, no. 6, pp. 5042-5050, Nov. 2016.

[16] A. Rolán, F. Córcoles, and J. Pedra, "Doubly fed induction generator subject to symmetrical voltage sags," IEEE Trans. Ener. Conv., vol. 26, no. 4, pp. 1219-1229, Dec. 2011.

[17] A. Rolán, F. Córcoles, and J. Pedra, "Behaviour of the doubly fed induction generator exposed to unsymmetrical voltage sags," IET Elec. Power App., vol. 6, no. 8, pp. 561-574, Sep. 2012.

[18] A. Camacho, M. Castilla, J. Miret, A. Borrell, and L. García de Vicuña, "Active and reactive power strategies with peak current limitation for distributed generation inverters during unbalanced grid faults," IEEE Trans. Ind. Electron., vol. 62, no. 3, pp. 1515-1525, Mar. 2015.

[19] B. Mahamedi, M. Eskandari, J. E. Fletcher, and J. Zhu, "Sequencebased control strategy with current limiting for the fault ride-through of inverter-interfaced distributed generators," IEEE Trans. Sust. Ener., vol. 11, no. 1, pp. 165-174, Jan. 2020.

[20] A. Rolán, P. Giménez, S. J. Yagüe, S. Bogarra, J. Saura, and M. Bakkar, "Voltage recovery influence on three-phase gridconnected inverters under voltage sags," IET Gener. Transm. Distrib., vol. 13, no. 3, pp. 435-443, Feb. 2019.

[21] A. Rolán, P. Giménez, S. J. Yagüe, and S. Bogarra, "Modeling and control of a three-phase grid-connected inverter under fault conditions," in Proc. Int. Symp. Power Electron. Elec. Driv. Autom. Mot., Amalfi, Italy, Jun. 2018, pp. 479-484.

[22] J. D. Lawrence, A Catalog of Special Plane Curves. NY, NY, USA: Dover Publications Inc., 2014, pp. 113-117.

[23] R. Vidal-Albalate, H. Beltran, A. Rolán, E. Belenguer, R. Peña, and R. Blasco-Gimenez, "Analysis of the performance of mmc under fault conditions in hvdc-based offshore wind farms," IEEE Trans. Power Deliv., vol. 31, no. 2, pp. 839-847, Apr. 2016.

[24] K. Wang, Y. Li, Z. Zheng, and L. Xu, "Voltage balancing and fluctuation-suppression methods of floating capacitors in a new modular multilevel converter," IEEE Trans. Ind. Electron., vol. 60, no. 5, pp. 1943-1954, May 2013.

[25] Q. Tu, Z. Xu, Y. Chang, and L. Guan, "Suppressing dc voltage ripples of mmc-hvdc under unbalanced grid conditions," IEEE Trans. Power Deliv., vol. 27, no. 3, pp. 1332-1338, Jul. 2012. 